\title{
Formação de público para o cinema nacional e a potencialidade das salas independentes de cinema
}

\author{
Formación de público para el cine brasileño y la potencialidad de lãs \\ salas independientes
The potential of independent movie theaters in Training the Brazilian public for Brazilian cinema

Mateus Brum de Armas ${ }^{1}$

Felipe de Andrade Nunes Pereira Zamana ${ }^{2}$

\begin{abstract}
Resumo
Este documento visa discutir as problemáticas da distribuição e exibição dos filmes nacionais, tal como a dificuldade do acesso à cultura cinematográfica brasileira, histórico das leis de incentivo e seu fundamental impulso no cinema nacional, a homogenia dos filmes norte-americanos e analisar as salas independente de cinema Cine UFPel como possível formador de público local e uma janela alternativa em potencial.
\end{abstract}

Palavras-Chave: distribuição; filme brasileiro; leis de incentivo; rede.

\section{Resumen}

Este documento pretende discutir las problemáticas de la distribución y exhibición de las películas brasileñas, como la dificultad del acceso a la cultura cinematográfica, histórico de las leyes de incentivo y su fundamental impulso en La arte de el país, la homogeneización de las películas norteamericanas y analizar a sala independientes de cine Cine UFPel como posible formador de público local y potencial alternativa.

Palabras claves: distribución; leyes de incentivo; película brasileña; red.

\begin{abstract}
This document aims to discuss the problems of the distribution and exhibition of national films, such as the difficulty of access to the Brazilian film culture, history of the laws of incentive and its fundamental impulse in the national cinema, the homogeny of the North American films and analyze the independent room of Cine Cine UFPel as a possible local public educator and a potential alternative window.
\end{abstract}

Keywords: distribution; Brazilian film; incentive laws; network.

\footnotetext{
${ }^{1}$ Bacharel em Cinema e Audiovisual na Universidade Federal de Pelotas (UFPel); Centro Latino-Americano de Estudos em Cultura - CLAEC; Pelotas, Rio Grande do Sul, Brasil; mateus.armas@ gmail.com

${ }^{2}$ Bacharel em Direito pela Universidade Federal do Rio Grande (FURG); Centro Latino-Americano de Estudos em Cultura - CLAEC; Rio Grande, Rio Grande do Sul, Brasil; felipedean@ gmail.com
} 


\section{Introdução}

O contato entre o cinema nacional e o público brasileiro é extremamente raso, de forma que, a maioria da população sequer tem conhecimento sobre a quantidade de longas e curtas metragens sendo produzidos no país. Por estimativa, acredita-se que, atualmente, o Brasil produz mais de 150 filmes de longa-metragem, dos quais, aproximadamente 100 a 120 conseguem estrear em salas de cinema comerciais. Desses que chegam às salas, quatro ou cinco atingem a marca de um milhão de espectadores - número considerado sucesso de público no território nacional (SILVA, 2011).

Por outro lado, não é raro presenciar um filme norte-americano ultrapassar um milhão de espectadores no Brasil, a trilogia "Jogos Vorazes" de Gary Ross, por exemplo, em seu terceiro filme titulado no Brasil como "A Esperança - Parte um" dirigido por Francis Lawrence obteve uma bilheteria no Brasil de 1,3 milhões de espectadores apenas em um final de semana. Em 2014, o campeão no ranking foi o longa dirigido por Josh Boone: "A Culpa é Das Estrelas" com 6,2 milhões de espectadores, seguido por "Malévola” de Robert Stromberg com 5,8 milhões conforme a Figura 1.

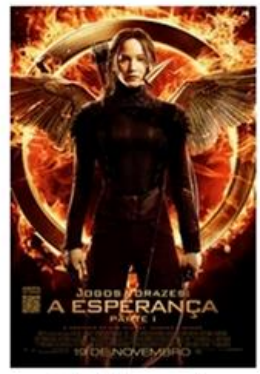

$1,3 \mathrm{mi}$

em um final

de semana

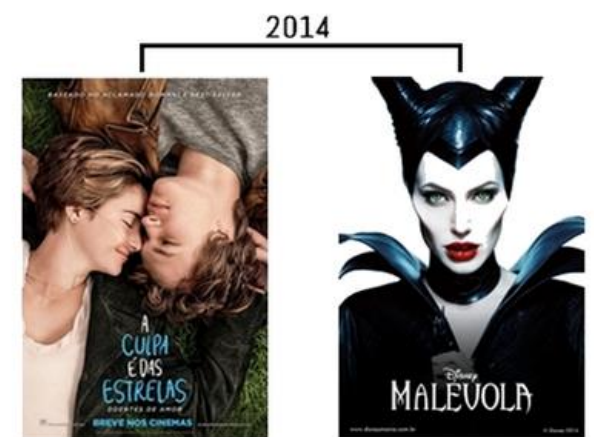

$6,2 \mathrm{mi}$

$5,8 \mathrm{mi}$

Figura 1 - Pôster dos filmes citados e suas respectivas Bilheterias.

Fonte: Google imagens

Analisando os dados apontados acima, é notável a disparidade do público em relação ao cinema brasileiro e ao hollywoodiano, o problema é consequência de uma série de fatores, dentre eles está a extrema carência que o audiovisual brasileiro tem em relação à distribuição e exibição. 


\section{Etapas no processo de produção fílmica}

O mercado audiovisual divide-se fundamentalmente em três etapas: produção, distribuição e exibição: A produção é todo processo antes e durante o filme ser gravado, desde a elaboração do roteiro, escolha do elenco e equipe técnica, agendas, dias de gravação, e principalmente: captação de recursos para o filme. Essa captação de recursos ocorre de diversas maneiras, no caso do Brasil os editais de incentivo à cultura transformaram as possibilidades de tornar palpável um projeto fílmico.

Seguido da produção, inicia-se o processo de distribuição, que principalmente no caso de filmes comerciais já é pensado juntamente com o roteiro, a distribuição é o processo de marketing, é o esforço para chegar ao público alvo e instiga-lo a querer consumir o filme. Após a distribuição vem o processo de exibição, que é onde vai haver o contato do público com o filme, isso pode ocorrer através de diversas janelas: internet, festivais, televisão, salas de cinema, etc. $\mathrm{O}$ cinema Brasileiro conseguiu se estabelecer fundamentalmente através das leis de incentivo à cultura: que tornam possível a captação de recursos para a realização do filme, no entanto ainda há uma grande deficiência nos setores da distribuição e principalmente no da exibição.

\subsection{Captação de recursos: leis de fomento à cultura cinematográfica}

A cultura de produção cinematográfica no Brasil sempre foi contrariada do favorecido e tem um histórico de altos e baixos, em 1986 é criada uma lei que planejava facilitar a captação de recursos para a produção dos filmes nacionais: a Lei Sarney, Lei n ${ }^{\circ} 7.505$, de 2 de julho de 1986, foi uma alavanca para o cinema no Brasil, sendo primeira Lei Federal de Incentivos Fiscais à Cultura do Brasil. José Sarney apresentou um projeto de lei para conceder benefícios fiscais na área do Imposto de Renda a toda operação de caráter cultural ou artístico (BELÉM, 2013,pg 2).

Esta lei prevaleceu até o ano de 1990 e nunca foi sistematicamente avaliada. Mesmo tendo tido uma vigência relativamente curta, ela é um objeto gerador de controvérsias pela sua sistemática, que pautada no simples cadastramento do proponente, deu margem a uma sequência de fraudes, o que leva a ainda hoje, não se conhecer ao certo o destino da aplicação dos recursos deste período (GRUMAN, 2010).

Retirada no governo Collor, em um descomprometimento do estado com a cultura, a lei Sarney sofre algumas alterações e finalmente em 1991 retorna como Lei Rouanet, Lei $n^{\circ}$ 8.313, de 23 de dezembro de 1991. Funcionando como sistema de abatimento de uma 
porcentagem dos impostos de empresas que, desta vez com necessidade de prestação de contas, uma tentativa de desvincular a produção e preservação cultural da instável verba pública, mas mantendo o compromisso constitucional do Estado de "apoiar e incentivar" a cultura, o Brasil optou por uma saída que envolvia uma parceria com o setor privado.

O maior exemplo veio de países como França, cujo modelo mescla o pesado investimento público do país europeu com a prática de mecenato - que envolve patrocínio ou doação de empresas ou pessoas físicas a artistas (RONCOLATO, 2018). A Lei Rouanet foi viés fundamental para a realização da maior parte dos grandes filmes brasileiros como o premiado “Aquarius” de Kleber Mendonça Filho.

\section{Hemogenia Globo Filmes}

Muitos dos filmes brasileiros que entram nas salas de cinema são distribuídos pela rede Globo Filmes, uma coprodutora de cinema brasileira integrante do Grupo Globo. Em 2013 a distribuidora era a responsável pelos 10 filmes nacionais com maior bilheteria nas salas de cinema do país, dentre eles "Minha Mãe é Uma Peça" de André Pellenz, com 4,6 milhões e "Meu Passado Me Condena" de Julia Rezende com 3,1 milhões. Os filmes da distribuidora não costumam apresentar inovação em suas tramas, tendo quase como característica principal a extensiva repetição de clichês e reciclagem de ideias anteriormente usadas, tornando os filmes previsíveis e desinteressantes para certos grupos.

No entanto, apesar da rede Globo Filmes não ser a única distribuidora brasileira, ela é uma das poucas que consegue atingir as salas de cinema em grande escala, ocasionando o fato de que quaisquer outros filmes que não sejam distribuídos por esta rede acabem não alcançando o grande público.

As consequências geradas por um público sem contato com a arte nacional, principalmente quando falamos de audiovisual, que é uma das ferramentas mais poderosas de influência e impacto em nossa sociedade, são devastadoras. Partindo do princípio de analisar cinema como instrumento pedagógico, transmissor de informações na contemporaneidade, imersos numa cultura da imagem, alguns desses aprendizados ocorrem com naturalidade. No entanto, assistir um filme, seja para entreter-se com ele, seja para analisá-lo, pressupõe aprendizagens específicas.

Os filmes são produções em que a imagem em movimento, aliada as múltiplas técnicas de filmagem e montagem e ao próprio processo de produção e ao elenco selecionado, cria um sistema de significações. São histórias que nos interpelam de um modo avassalador porque 
não dispensam o prazer, o sonho e a imaginação. Elas mexem com nosso inconsciente, embaralham as fronteiras do que entendemos por realidade e ficção. Quando dizemos que o cinema cria um mundo ficcional, precisamos entendê-lo como uma forma de a realidade apresentar-se (PINTO, 1936).

Em detrimento da exposição extrema a tantos filmes norte-americanos, o espectador acaba criando certa ideologia "romantizada" da cultura norte-americana, esquecendo-se ou até desvalorizando a arte nacional, justamente por apenas ter contato com o mesmo tipo de filme norte-americano. Esse "complexo de vira-lata' torna-se preocupante à medida que o indivíduo menospreza a cultura nacional e vangloria uma cultura estrangeira, o que é um fato bastante infeliz em uma sociedade tão rica culturalmente como é o Brasil. As salas de cinema independente têm se apresentado como a melhor forma de se solucionar o problema, estreitando os muros entre público e cinema. Essas salas surgem a partir da necessidade de ter-se contato com filmes de difícil circulação por conta das estruturas fechadas de dominação do produto estrangeiro.

\section{Sala Independente de Cinema: Cine UFPel}

Em 2015, foi inaugurada na cidade de Pelotas o Cine UFPel: um espaço para exibição de filmes nacionais em sessões gratuitas, com o objetivo de formar espectadores e proporcionar a comunidade o acesso à cinematografias não hegemônicas. A programação da sala visa dar conta da pluralidade do cinema, de forma que não se aproxime de uma sala comercial, mas também que não sejam exibidos apenas filmes extremamente herméticos, já que o objetivo é a conexão com o público em geral e este, muitas vezes, não possui referencial para se relacionar com determinadas obras (LANGIE, 2015).

O Cine UFPel realiza uma série de ações, todas voltadas a exibição gratuita de cinema não comercial. O destaque são as sessões de quintas e sextas feiras às $19 \mathrm{~h}$, de filmes brasileiros contemporâneos. Além disso, quinzenalmente há sessões especiais para idosos do asilo, sessões para alunos da rede pública no turno da manhã, cineclubes e sessões para diversos cursos da UFPel. Semestralmente a sala expõe os trabalhos realizados pelos alunos dos cursos de Cinema e Audiovisual e Cinema de Animação. Recentemente foi realizada uma sessão de cinema acessível em parceria com o Banrisul, foi exibido um filme legendado, com libras e descrição de áudio, os espectadores receberam também uma venda para os olhos, tornando assim, possível se colocar na posição de um deficiente visual. A sessão comoveu 
bastante o público presente, e recebeu vários elogios deixando assim, a grande probabilidade de continuação do projeto.

Além das sessões especiais, mostras de trabalho e exibição de filmes nacionais inéditos, o Cine UFPel também trouxe alguns cineastas para falarem de suas experiências e suas obras, dentre eles estão Rene Goya Filho, Alexandre Derlam, Bebeto Alves, Filipe Matzembacher, Marcio Reolon, Jean-Claude Bernardet, Luiz Rosemberg Filho e a fundadora da Vitrine Filmes, Silvia Cruz que falou sobre a distribuição no cinema. Todos os contatos com profissionais atuantes no mercado foram de extrema importância para os acadêmicos dos cursos de cinema, as mostras semestrais dos trabalhos também influenciam diretamente na formação dos mesmos, em relação a testes de público, saber se um filme funcionou ou não com determinado público. É algo fundamental e que poucos cineastas, especialmente estudantes, tem contato com esse tipo de experiência que o Cine UFPel proporciona.

\subsection{Interesse do público por novos caminhos}

No ano de 2017, a Agência Nacional do Cinema - ANCINE registrou que o Brasil teve 158 títulos lançados em salas de exibição. Sendo este um número recorde de lançamentos brasileiros desde 1995, e representando aumento de 11,3\% em relação a 2016, que obteve 142 títulos. Conforme a figura abaixo:

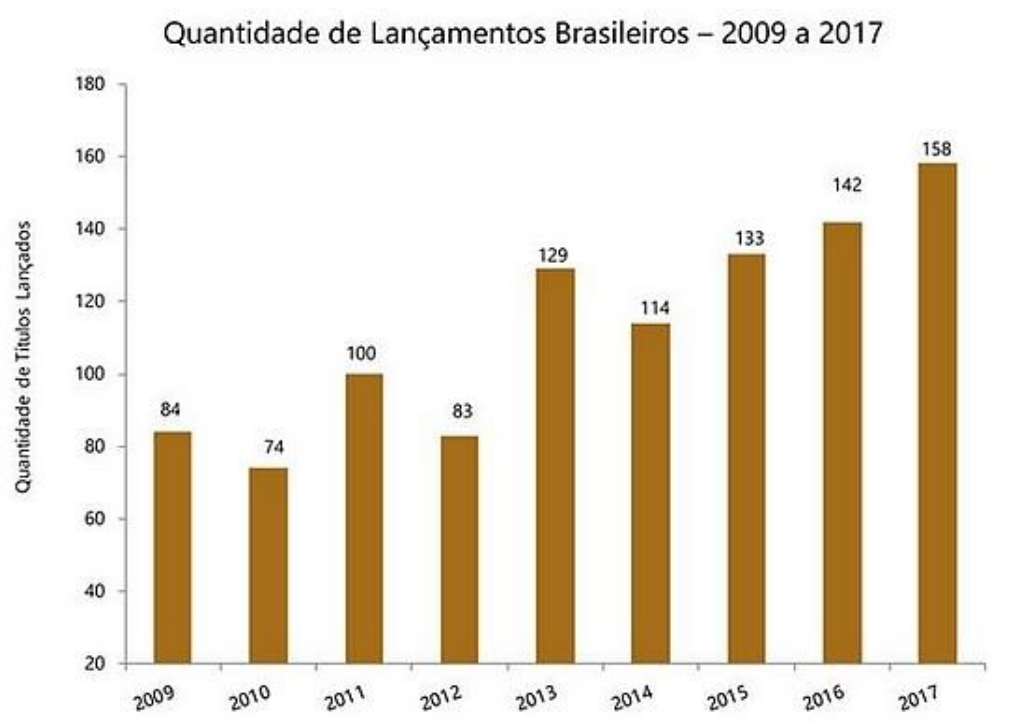

Figura 3 - Quantidade de Lançamentos Brasileiros - 2009 a 2017

Fonte: ANCINE 
O filme brasileiro com maior bilheteria até os dias de hoje foi "Tropa de Elite 2" de José Padilha em 2010, pertencente a Globo Filmes, com 11 milhões de espectadores. O grande sucesso do filme e a espantosa diferença de bilheteria entre "Tropa de Elite" e qualquer outro filme nacional, nos mostra a necessidade e interesse do público por ser representado na tela. $\mathrm{O}$ filme com temática social aborda uma realidade muito mais próxima da maioria dos brasileiros do que os filmes de comédia sobre a classe média alta, além disso, o filme trouxe uma atmosfera diferente dos outros filmes distribuídos pela Globo Filmes.

A produção contemporânea do cinema brasileiro reflete um contexto marcado pela multiplicidade cultural, pela globalização desenfreada e por uma complexidade maior da sociedade brasileira (SANTOS, 2011), existem muitos filmes em produção no Brasil, que, não conseguem chegar as grandes massas por problemas de viabilidade de distribuição, os poucos filmes que chegaram às salas de cinema, sem a distribuição da Globo Filmes, obtiveram uma excelente recepção do público em relação a quantidade de salas que foram distribuídos.

O longa "Hoje Eu Quero Voltar Sozinho" de Daniel Ribeiro, por exemplo, que retrata a história de um deficiente visual que descobre sua homossexualidade estreou em apenas dezoito cidades do país em 33 salas de cinema no ano 2014, obteve um público maior que 33 mil espectadores, tornando-se o quinto filme mais visto da semana, três semanas depois a bilheteria do filme já tinha alcançado 167 mil espectadores.

As salas de cinema independente têm funcionado como um grande conector entre os filmes não distribuídos pela Globo Filmes, e possibilitando ao público o acesso à filmes dos quais possam se identificar ou até mesmo apreciar um modelo diferente do que é produzido comercialmente. É uma ação de fuga do modelo cultural hegemônico, que pode operar alguma transformação, mesmo que seja microtransformação (LANGIE, 2015).

Em relação ao Cine UFPel, sala de cinema independente sendo analisada na pesquisa, em termos de inovação, possibilitou o contato direto da comunidade e dos alunos com cinema brasileiro, diretores, distribuidores e profissionais atuantes no mercado, em apenas um ano de existência a sala já realizou diversas sessões, mostras especiais e festivais de cinema.

Mobilizando e atingindo um público cada vez maior, estimulando a circulação de artistas nacionais e possibilitando o contato com o cinema de pessoas que normalmente não teriam condições de pagar para frequentar uma sala de cinema comercial. A sala ainda precisa de algumas reformas, e um dos principais objetivos para o futuro do projeto é investir ainda mais na divulgação do mesmo, para que assim, os resultados em longo prazo sejam maiores.

O cinema provoca sensações no público que ativam o pensamento, o choque muitas vezes provocado pelas imagens permite ao sujeito pensar o impensável, criando novas 
paisagens, fazendo-o sair de sua zona de conforto e, assim, ativando seu senso crítico sobre o mundo. As sessões de filmes que, de forma periódica e gratuita, não se enquadram no “cinema comercial”, revelam-se, então, como potência na formação estética e política do sujeito espectador (LANGIE, 2015).

\section{Conclusões}

O "'complexo de vira-lata" é um problema grave difundido entre a sociedade, a hegemonia de distribuição dos blockbusters hollywoodianos causa prejuízo social (LANGIE, 2011). O público brasileiro poderia apreciar mais e valorizar a cultura nacional, se tivesse conhecimento da cinematografia nacional, principalmente em relação ao cinema mais artístico.

Os filmes brasileiros precisam circular entre a população, o público precisa conhecer o que está sendo feito fora das comédias clichês distribuídas em grande escala por distribuidoras potentes, entrando em contato com formatos de maior variedade, diversidade e representatividade. A diversidade cultural e o reconhecimento das minorias começam a ser requisitos para que a globalização seja menos injusta e mais inclusiva (CANCLINI, 2009, p. 253).

Desse modo, as salas independentes mostram potencialidade para minimizar o domínio do produto comercial, e estreitar esses muros entre o público e o cinema nacional, expandindo o horizonte dos espectadores.

\section{Referências}

BELÉM, M.; DONADONE, J. A Lei Rouanet e a construção do "mercado de patrocínios culturais". NORUS. Pelotas, v. 1, n. 1, São Paulo, 2013. Disponível em <https://periodicos.ufpel.edu.br/ojs2/index.php/NORUS/article/view/2761>. acessos em 15 out. 2018.

VEYNE, B. O Sistema Francês de apoio ao cinema. São Paulo, 2009. Disponível em $\langle$ https://www.cinefrance.com.br/arquivos/o_sistema_frances_de_apoio_ao_cinema.pdf $>$. acessos em 15 out. 2018.

LANGIE, C. As Potencialidades estéticas e políticas do Cine UFPel. Expressa Extensão. Pelotas, v. 20, n. 2, 2015. Disponível em <https://periodicos.ufpel.edu.br/ojs2/index.php/expressaextensao/article/view/7673/5577>. acessos em 15 out. 2018.

XAVIER, Ismail. Corrosão social, pragmatismo e ressentimento: vozes dissonantes no cinema brasileiro de resultados. Novos estud. - CEBRAP, São Paulo, n. 75, p. 139-155, jul 
2006. Disponível em <http://www.scielo.br/scielo.php?script=sci_arttext\&pid=S0101$33002006000200010 \& \operatorname{lng}=$ en\&nrm=iso>. acessos em 15 out. 2018.

SANTOS, Roberto Elísio dos. 2 Vezes 5 Vezes Favela: aproximações e distanciamentos do cinema brasileiro. Intercom, Rev. Bras. Ciênc. Comun., São Paulo, v. 34, n. 2, p. 75-91, dez. 2011. Disponível em <http://www.scielo.br/scielo.php?script=sci_arttext\&pid=S1809$58442011000200005 \& \operatorname{lng}=$ pt\&nrm=iso $>$. acessos em 15 out. 2018.

TRINDADE, A. D. O descobrimento no pensamento cinematográfico brasileiro: diálogos possiveis quanto à identidade nacional. Lua Nova, São Paulo, n. 81, 2010. Disponível em < http://www.scielo.br/pdf/ln/n81/a04n81.pdf>. acessos em 15 out. 2018.

MENEZES, R. L. M. S. Entre o blockbuster e o cinema independente: a distribuição nas salas de cinema brasileiras e o caso de o som ao redor. In: XV Congresso de Ciências da Comunicação na Região Nordeste, 2013, Mossoró, RN. Anais (online). Mossoró: Intercom, 2013. Disponível em <http://portalintercom.org.br/anais/nordeste2013/resumos/R37-07031.pdf $>$. acessos em 15 out. 2018.

SILVA, J. G. B. R. E.: Assimetrias, dilemas e axiomas do cinema brasileiro nos anos 2000. Revista Famecos, Porto Alegre, v. 18, n. 3, p. 916-932, dez. 2011. Disponível em $<$ http://revistaseletronicas.pucrs.br/ojs/index.php/revistafamecos/article/view/10389/7289>. acessos em 15 out. 2018.

FABRIS, E. H.: Cinema e educação: um caminho metodológico. Educação e Realidade. São Paulo, v. 33, n. 1, 2008. Disponível em <https://seer.ufrgs.br/educacaoerealidade/article/view/6690>. acessos em 15 out. 2018.

ANCINE. Brasil fecha 2017 com recorde de lançamentos de filmes nacionais. Brasília, 2018. Disponível em < https://www.ancine.gov.br/pt-br/sala-imprensa/noticias/brasil-fecha2017-com-recorde-de-lan-amentos-de-filmes-nacionais>. acessos em 12 jan. 2018. 